\title{
Endogenous lipid mediators in the resolution of airway inflammation
}

\author{
O. Haworth and B.D. Levy
}

ABSTRACT: Acute inflammation in the lung is fundamentally important to host defence, but chronic or excessive inflammation leads to several common respiratory diseases, including asthma and acute respiratory distress syndrome.

The resolution of inflammation is an active process. In health, events at the onset of acute inflammation establish biosynthetic circuits for specific chemical mediators that later serve as agonists to orchestrate a return to tissue homeostasis. In addition to an overabundance of proinflammatory stimuli, pathological inflammation can also result from defects in resolution signalling.

The understanding of anti-inflammatory, pro-resolution molecules and their counter-regulatory signalling pathways is providing new insights into the molecular pathophysiology of lung disease and opportunities for the design of therapeutic strategies.

In the present review, the growing family of lipid mediators of resolution is examined, including lipoxins, resolvins, protectins, cyclopentenones and presqualene diphosphate. Roles are uncovered for these compounds, or their structural analogues, in regulating airway inflammation.

KEYWORDS: Acute respiratory distress syndrome, asthma, inflammation, lipoxins, mediators, resolution

nflammation of the lungs and airways has a significant medical and economic burden in both Europe and the USA [1]. Asthma has the highest morbidity amongst inflammatory lung diseases and its incidence has doubled since the 1980s [2]. Asthma is characterised by airway infiltration of eosinophils, T-cells and mast cells with excess mucus, and, in some cases, airway remodelling with changes in smooth muscle, which together contribute to the clinical hallmark of airflow obstruction. Acute respiratory distress syndrome (ARDS) is the inflammatory lung disease with the highest mortality [3]. ARDS is characterised by extensive inflammation with polymorphonuclear leukocyte (PMN) activation in the lungs [3]. The chronic inflammation of asthma and exuberant acute inflammatory response in ARDS represent two different ends of a spectrum of inflammatory lung disease, yet both of these respiratory illnesses are characterised by an inability to limit inflammation.

Inflammation is a physiological response to tissue injury, infection and allergen challenge that evolved to limit damage from noxious agents and the spread of infectious organisms [4]. The inflammatory response is inherently protective and intimately involved in the restoration of tissue homeostasis. Until recently, the resolution of inflammation has been an under-represented focus of inflammation research. It is now clear that the resolution phase of an inflammatory response is an active and orchestrated process, similar in complexity to the onset and maintenance of inflammation [5]. In restoring tissue homeostasis, resolution not only dampens inflammation, but also promotes immune defence mechanisms. The process of resolution has its origins at the beginning of the inflammatory response, with the establishment of biosynthetic circuits for later production of counterregulatory chemical mediators. Molecules that promote resolution are inherently different from purely anti-inflammatory compounds, as proresolution molecules contribute to tissue catabasis, returning the tissue to normal $[6,7]$.

Five classes of naturally occurring pro-resolution molecules are reviewed in the present study (fig. 1), in addition to their signalling pathways, role in restoring tissue homeostasis and impact on cellular effectors of lung inflammation (table 1).

\section{AFFILIATIONS}

Pulmonary and Critical Care Medicine, Brigham and Women's Hospital and Harvard Medical School, Boston, MA, USA.

\section{CORRESPONDENCE}

B.D. Levy

Pulmonary and Critical Medicine Brigham and Women's Hospital

75 Francis Street Boston MA 02115 USA

Fax: 16172324623

E-mail: blevy@partners.org

Received:

January 162007

Accepted after revision:

June 152007

SUPPORT STATEMENT

This work was supported in part by the National Institutes of Health (Bethesda, MD, USA; HL68669, Al068084 and DE016191).

STATEMENT OF INTEREST A statement of interest for B.D. Levy can be found at www.erj.ersjournals.com/misc/ statements.shtml 
a)<smiles>CCCCC[C@H](O)/C=C/C=C/[C@H](O)[C@@H](O)CCCCC(=O)O</smiles>

d)

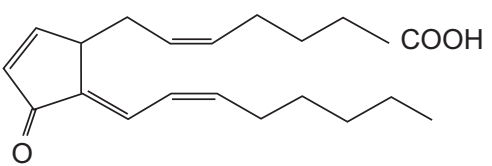

b)

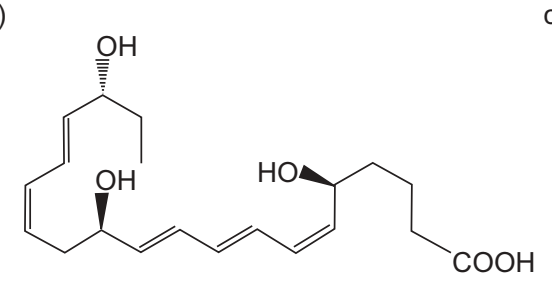

c)

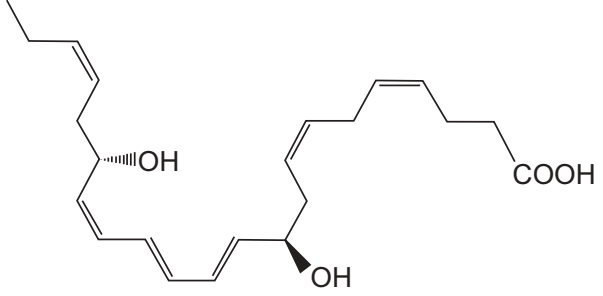

e)

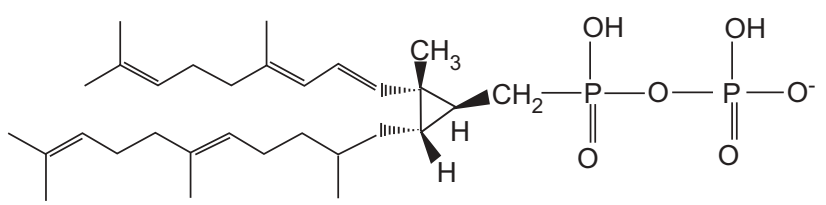

$\mathrm{OH}$

FIGURE 1. Classes of endogenous anti-inflammatory lipids. Representative members of five classes of endogenous anti-inflammatory lipids are shown: a) lipoxins, lipoxin $\mathrm{A}_{4}$; b) resolvins, resolvin $\mathrm{E} 1$; c) protectins, protectin $\mathrm{D} 1$; d) cyclopentenones, 15 deoxy $\Delta^{12-14}$ prostaglandin $\mathrm{J}_{2}$; and e) polyisoprenyl phosphates, presqualene diphosphate.

\section{CHEMICAL MEDIATORS OF RESOLUTION}

\section{Lipoxins}

Lipoxins (LXs) are lipoxygenase (LO) interaction products of arachidonic acid (C20:4) metabolism with structures and biological properties distinct from other eicosanoids [35, 36]. LXs have potent anti-inflammatory properties with cell typespecific actions on leukocytes, endothelium, epithelia and other stromal cells (fig. 2; table 1). Of particular relevance for the resolution of inflammation in asthma and ARDS, LXs inhibit eosinophil trafficking $[12,13,37]$ and PMN chemotaxis, trans-migration across post-capillary venules, generation of superoxide anions and degranulation of azurophilic granules [6]. In addition, LXs stimulate clearance of apoptotic PMNs by macrophages [18], block natural killer cell cytotoxicity and tumour necrosis factor (TNF)- $\alpha$ release from T-cells $[14,15]$.

LXs are formed via transcellular biosynthesis with intermediates transferred in a bi-directional manner between cells [38]. LXs can be generated via at least three distinct pathways. One pathway involves leukocyte 5-LO-catalysed conversion of C20:4 to leukotriene (LT) $\mathrm{A}_{4}$, which, in the vasculature, is subsequently taken up by platelets and converted into $\mathrm{LXA}_{4}$ by 12-LO [39]. A second pathway involves the conversion of epithelial cell-, eosinophil- or monocyte-derived C20:4 by 15LO, producing 15(S)-hydroperoxyeicosatetraenoic acid, which can also serve as a substrate for leukocyte 5-LO. This reaction generates an unstable epoxytetraene intermediate that is converted to LXs by hydrolases [35, 40]. 5-LO derived $\mathrm{LTA}_{4}$ can also be converted by 15-LO to LXs. Although these three pathways are the principal means of LX generation, additional 5-LO-independent pathways probably exist.

Interestingly, aspirin, the lead nonsteroidal anti-inflammatory drug, inhibits prostaglandin (PG) synthesis, but at doses much lower than the dose needed to exert its anti-inflammatory effects [41]. This paradox was recently addressed by the identification of the aspirin-triggered 15-epimer-LXs (ATLs) [42]. Aspirin acetylates the active site of cyclooxygenase (COX)-2 to inhibit production of PGs, but the enzyme is still able to convert C20:4 to 15(R)-hydroxyeicosatetranoic acid (15R-HETE). This compound can serve as a substrate for 5-LO for further conversion to ATLs [42]. 15-epimer-LXs increase nitric oxide synthesis via constitutive or inflammatory nitric oxide synthase, and nitric oxide decreases leukocyte-endothelial cell interactions inhibiting leukocyte accumulation within inflamed tissues [43]. Thus, aspirin can exert anti-inflammatory effects by both inhibiting pro-inflammatory PG biosynthesis and promoting the formation of anti-inflammatory 15epimer-LXs. In the absence of aspirin, 15R-HETE can also be produced by cytochrome p450 enzymes to act as a substrate for 15-epimer-LX transcellular biosynthesis [44, 45].

LXs are metabolically inactivated by the actions of 15hydroxyprostaglandin dehydrogenase and PG reductase to form 13,14-dihydro-15-hydroxy-LXA 4 [9, 46]. LX and 15epimer-LX metabolism is stereospecific, with 15-epimer-LXs metabolised less efficiently, thereby increasing the biological half-life of these ATLs approximately two-fold [46]. LX analogues that resist inactivation have been generated [9]. These modifications enhance the biological activity of LXs and have proved to be useful tools in the study of the biological functions of LXs in vitro and in vivo.

LXs not only play a role directing leukocyte function towards resolution, but can also signal the local stromal microenvironment towards resolution (table 1). Normal human bronchial epithelial cells (NHBE) exposed to hydrochloric acid increase expression of COX-2 and the high-affinity $\mathrm{LXA}_{4}$ receptor ALX. $\mathrm{LXA}_{4}$ promotes restitution from acid injury by increasing basal NHBE proliferation and inhibiting proinflammatory events in differentiated NHBE, such as cytokine release and PMN trans-migration [26]. Despite potent regulation of epithelial cell and leukocyte function, LX bioactions are distinct from immunosuppressive compounds, in that LX signalling regulates pathogen-mediated inflammation [20,47] and promotes mucosal bacterial killing via expression of bacterial/permeability inducing protein (BPI) in epithelial cells [22]. Thus, in addition to anti-inflammation, LXs are also host protective. 
TABLE 1 Cell type-specific counter-regulatory actions for chemical mediators of resolution

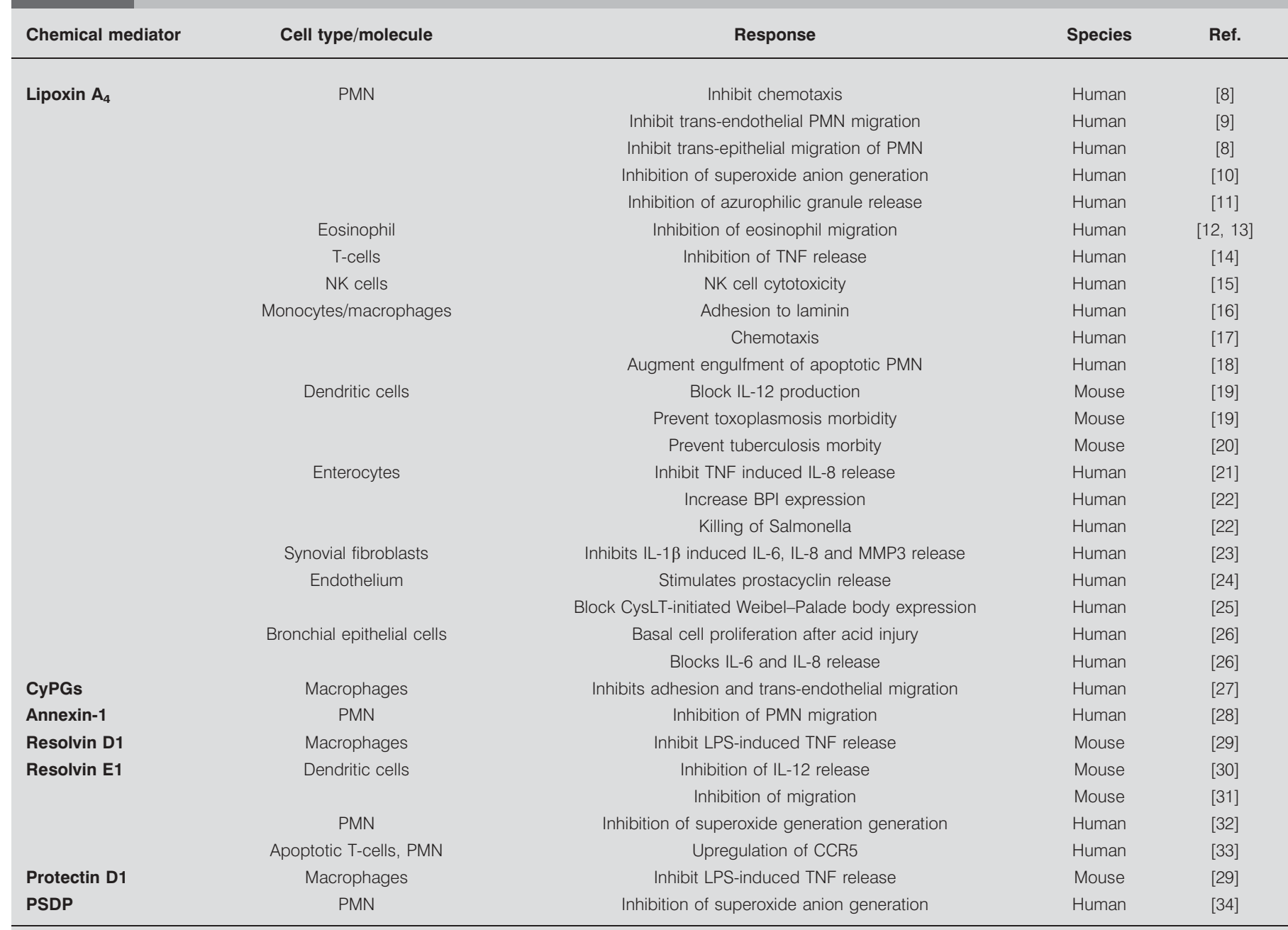

PMN: polymorphonuclear leukocyte; TNF: tumour necrosis factor; NK: natural killer; IL: interleukin; BPI: bactericidal/permeability increasing protein; MMP: matrix metalloproteinase; CysLT: cysteinyl leukotriene; CyPG: cyclopentenone prostaglandins; LPS: lipopolysaccharide; CCR: CC chemokine receptor; PSDP: presqualene diphosphate.

\section{$\mathrm{LXA}_{4}$ receptors}

LXs interact with one or more specific receptors, including their own specific receptor, a subclass of $\mathrm{LTD}_{4}$ receptors (i.e. cysteinyl (Cys)LT1), and additional intracellular recognition sites [48, 49]. The $\mathrm{LXA}_{4}$ receptor ALX is a G-protein-coupled protein that binds $\mathrm{LXA}_{4}$ with high affinity $\left(\mathrm{K}_{\mathrm{D}}=1.7 \mathrm{nM}\right)$ [48]. ALX was the initial receptor identified to bind both lipid and peptide ligands $[48,50]$. In PMNs, signalling by ALX occurs, in part, via polyisoprenyl phosphate (PIPP) remodelling (vide infra) [10] and inhibition of leukocyte-specific protein-1 phosphorylation, which is a downstream regulator of the p38-mitogen-activated protein kinase cascade (table 2) [51].

\section{ALX mediates annexin-1 anti-inflammatory signals}

Glucocorticoids are potent anti-inflammatory molecules that play a major role in resolving inflammation by inhibiting the production of pro-inflammatory mediators [58, 59] and decreasing the expression of leukocyte adhesion molecules [60]. Dexamethasone also promotes monocyte and T-cell emigration out of inflamed tissues [61, 62]. Glucocorticoids act via cognate receptors within the cell cytoplasm that, upon ligand binding, move to the nucleus to regulate transcription [63]. Of interest for asthma therapy, corticosteroids induce expression of ALX [64] and annexin-1, which can also interact with ALX to initiate anti-inflammatory signals [65].

Annexin-1 is a potent anti-inflammatory molecule that is abundantly expressed by PMNs [66]. Most of the annexin-1 is within the cytoplasm. Upon PMN activation and adhesion to inflamed vascular endothelium, annexin-1 is rapidly externalised [67], leading to cell detachment from inflamed blood vessels [68] and decreased PMN recruitment. The addition of antisera to annexin- 1 in a model of acute inflammation results in the persistence of PMNs in the inflammatory exudates [69]. In annexin-1 knockout mice, PMNs are more easily activated [28, 69]. Some of the anti-inflammatory effects of annexin-1 and its $\mathrm{N}$-terminal peptide, Ac2-26, are mediated by direct interactions with ALX, but at a lower affinity $\left(K_{D}=900 \mathrm{nM}\right)$ than $\mathrm{LXA}_{4}[70]$. 


\section{LXs increase epithelial cell} expression of BPI

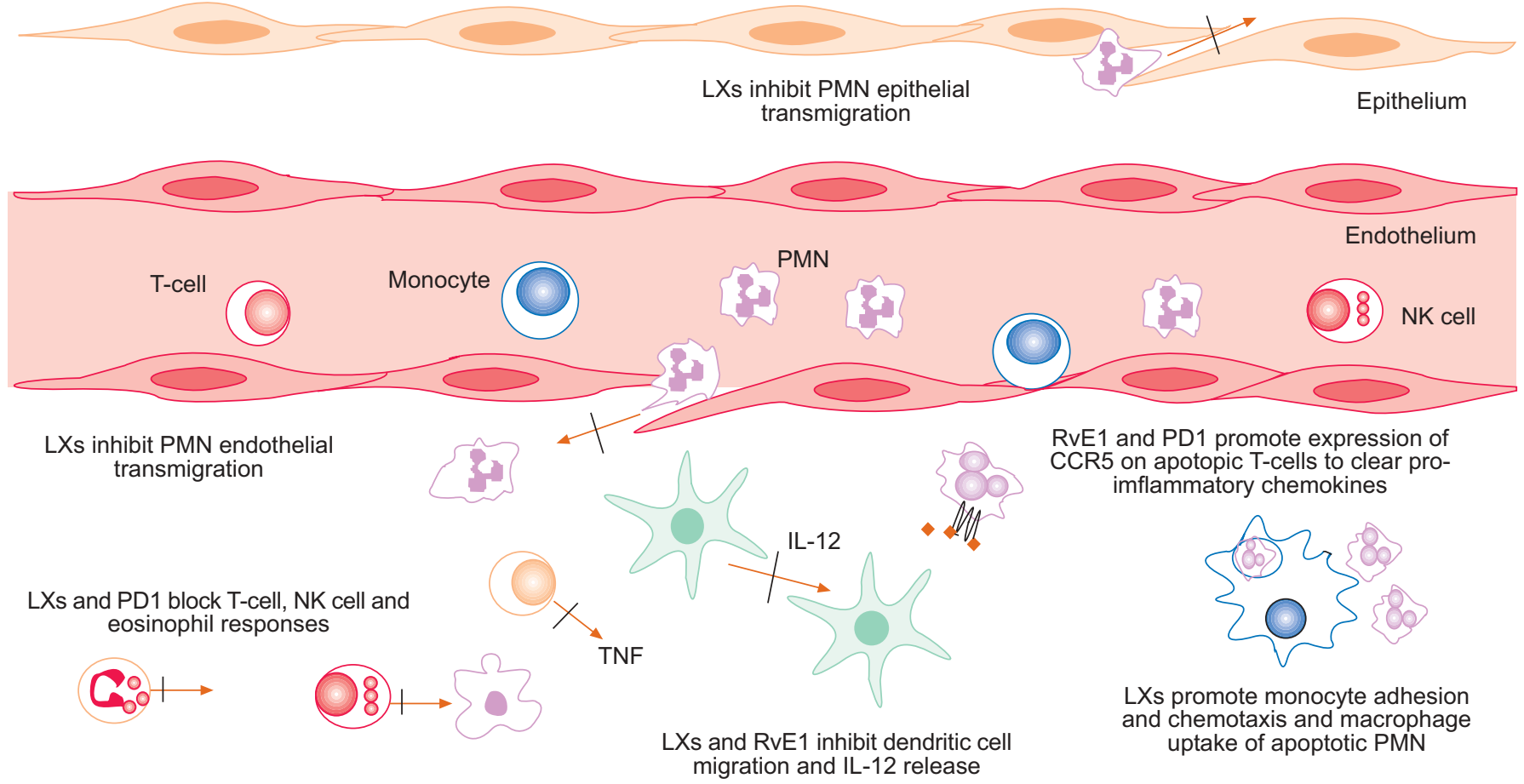

FIGURE 2. Cell-type specific counter-regulatory actions of some lipid mediators. Endogenous autacoids display cell type-specific actions to promote inflammation. Lipoxins (LXs) engage specific receptors (e.g. ALX) to inhibit polymorphonuclear leukocyte (PMN) transmigration through endothelial and epithelial cells, and can inhibit proinflammatory responses of innate immune effectors, including PMNs, T-cells, eosinophils and natural killer (NK) cells. Clearance of apoptotic PMN is also enhanced by LXs. Of interest, these compounds increase mucosal epithelial cell expression of bactericidal/permeability increasing protein (BPI) to protect against pathogens. Resolvins (e.g. resolvin $\mathrm{E}(\mathrm{RVE}) 1$ ) and protectins (e.g. protectin $\mathrm{D}(\mathrm{PD}) 1)$ also display cell type-specific counter-regulatory responses to promote resolution. CCR: CC chemokine receptor; TNF: tumour necrosis factor; IL: interleukin.

Role of LXs in lung disease

LXs are generated in the lung during a range of respiratory illnesses [71]. Of interest is the fact that a low biosynthetic capacity for LXs is associated with severe airway inflammation. Aspirin-exacerbated respiratory disease is a more severe and protracted form of asthma and, in whole blood, these

\section{TABLE 2 Counter-regulatory lipid mediator signalling mechanisms}

\begin{tabular}{|c|c|c|c|c|}
\hline Chemical mediator & Signalling molecule & Action & Species & Ref. \\
\hline \multirow[t]{5}{*}{ Lipoxin $\mathbf{A}_{4}$} & PIPP remodelling & Inhibits $\mathrm{LTB}_{4}$-stimulated PSDP conversion to PSMP & Human & [10] \\
\hline & LSP-1 & Blocked phosphorylation of LSP-1 & Human & [51] \\
\hline & socs-2 & Induces the expression of SOCS-2 & Mouse & [47] \\
\hline & Akt/PKB & Induces phosphorylation of $\mathrm{Myc} 9$ and $\mathrm{Cdc} 42$ polarisation & Human & [52] \\
\hline & PPAR- $\gamma$ and CINC- 1 & Reduced PPAR- $\gamma$ and CINC-1 levels in hepatocytes & Rat & [53] \\
\hline \multirow[t]{3}{*}{ CyPGs } & PPAR- $\gamma$ & Ligand for PPAR- $\gamma$ & Mouse & [54] \\
\hline & $\mathrm{NF}-\kappa \mathrm{B}$ & Suppression of NF-kB binding & Mouse & [54] \\
\hline & AP1 and STAT activity & Inhibition of AP1 binding to DNA & Mouse & [55] \\
\hline Resolvin E1 & $N F-\kappa B$ & Inhibition of NF-kB signalling & Mouse & [31] \\
\hline \multirow[t]{3}{*}{ PSDP } & PLD & Blocks PLD activation in PMN & Human & [10] \\
\hline & $\mathrm{SH}_{2}$ domains & Interacts with $\mathrm{SH}_{2}$ domains & Human & {$[56]$} \\
\hline & PI3K & Inhibits PI3K activity in PMN & Human & [57] \\
\hline
\end{tabular}

PIPP: polyisoprenyl phosphate; LT: leukotriene; PSDP: presqualene diphosphate; PSMP: presqualene monophosphate; LSP: leukocyte-specific protein; SOCS suppressor of cytokine signalling; PKB: protein kinase B; PPAR: peroxisome proliferator-activated receptor; CINC: cytokine-induced neutrophil chemoattractant; CyPG cyclopentenone prostaglandins; NF: nuclear factor; AP: activator protein; STAT: signal transducers and activators of transcription; PLD: phospholipase D; PMN polymorphonuclear leukocyte; $\mathrm{SH}_{2}$ : Src homology 2 domain; PI3K: phosphatidylinositol 3-kinase. 
asthmatic individuals have a decreased ability to produce LXs compared with aspirin-tolerant asthmatics [72]. In addition, lower levels of $\mathrm{LXA}_{4}$ are present in supernatants of induced sputum in severe, compared with mild, asthma [73]. Moreover, individuals with severe asthma have a reduced capacity, in whole blood, to convert C20:4 to 15-LO-catalysed products, including both 15-HETE and $\mathrm{LXA}_{4}$ [74]. In sharp contrast to this decrement in 15-LO activity, 5-LO-derived products, including 5-HETE, $\mathrm{LTB}_{4}$ and CysLTs, are all increased in severe asthma [74]. The forced expiratory volume in one second percent predicted values and circulating levels of $\mathrm{LXA}_{4}$ and CysLTs are correlated, suggesting a link between biosynthetic capacity for these bioactive lipid mediators and airflow obstruction in asthma. Thus, decrements in LX generation and increases in LT production in severe asthma create an imbalance that maintains the persistent airway inflammation and airflow obstruction typical of this condition.

Reduced levels of LXs have also been found in the airways of some patients suffering from cystic fibrosis [75]. Because similar results have been obtained with chronic bronchitis, altered LX formation in the airway may represent a more generalised consequence of chronic PMN-enriched airway inflammation [76]. In support of the notion that LXs might provide a viable therapeutic strategy in the treatment of respiratory inflammation, mice treated with a stable $\mathrm{LXA}_{4}$ mimetic have reduced airway inflammation, and transgenic mice for human ALX coupled to a component of the CD11b promoter have reduced leukocyte infiltration in murine models of allergic airway inflammation and acute lung injury (ALI) [37, 77].

\section{PGs and LTs}

Like LXs, PGs and LTs are also enzymatically derived from C20:4 and serve as potent lipid mediators [78]. They perform crucial functions in normal physiology and play important roles early in acute inflammation. At the onset of inflammation, C20:4 is metabolised by COXs to PGs, such as $\mathrm{PGD}_{2}$, $\mathrm{PGE}_{2}, \mathrm{PGF}_{2 \alpha}, \mathrm{PGI}_{2}$ and thromboxane $\mathrm{A}_{2}$, that are well known to have potent biological effects on inflammatory cells and lung tissues. In addition to the well-described roles of PGs in promoting inflammatory responses, recent studies have also highlighted a role for COX-2-derived PGs serving antiinflammatory and anti-fibrotic roles in the resolution of inflammation $[77,79,80]$. In a model of acute resolving pleural inflammation, COX-2 levels transiently increased early $(2 \mathrm{~h})$ and late $(48 \mathrm{~h})$ after the onset of inflammation to generate COX-2-derived $\mathrm{PGD}_{2}$ and 15deoxy $\Delta^{12-14} \mathrm{PGJ}_{2}\left(15 \mathrm{~d}-\mathrm{PGJ}_{2}\right)$ [79]. COX-2-derived $\mathrm{PGE}_{2}$ can also resolve allergic pleural inflammation $[79,80]$ and TNF-initiated PMN activation in exudates [81]. Of interest, COX-2 derived $\mathrm{PGD}_{2}$ and $\mathrm{PGE}_{2}$ can induce 15LO expression to promote LX biosynthesis [81]. In a model of spontaneously resolving ALI, selective COX-2 inhibition or deficiency results in prolonged inflammation, in part, by decreasing production of $\mathrm{PGE}_{2}$ and pro-resolving mediators, including $\mathrm{LXA}_{4}$ and 15 -epimer-LXA 4 [77, 79]. In addition to PGs, LTs also carry pro-phlogistic properties important for leukocytes and respiratory tissues [82]. Metabolism of C20:4 by 5 -LO leads to the formation of LTs. $\mathrm{LTA}_{4}$ is an unstable, yet pivotal intermediate that can be converted to $\mathrm{LTB}_{4}$ by $\mathrm{LTA}_{4}$ hydrolase, $\mathrm{LTC}_{4}$ by $\mathrm{LTC}_{4}$ synthase or to LXs by 12 - or $15-\mathrm{LO}$
[6]. In particular, $\mathrm{LTB}_{4}$ is a potent PMN chemoattractant and secretagogue, and $\mathrm{LTC}_{4}$ and $\mathrm{LTD}_{4}$ are potent bronchoconstrictors [82]. Of interest, $\mathrm{LTB}_{4}$ can be important for host defence, promoting PMN phagocytosis of pathogenic bacteria and antiviral mechanisms [83, 84]. These same properties are not shared by CysLTs, as mice deficient in the multidrug resistance protein 1, which is involved in cellular extrusion of $\mathrm{LTC}_{4}$, are resistant to Streptococcus pneumoniae-induced pneumonia [85], and a CysLT1-receptor selective antagonist provides a survival advantage in animal models of sepsis [86].

\section{Cyclopentenones}

The COX-derived intermediate $\mathrm{PGG}_{2}$ can be converted by $\mathrm{PGD}_{2}$ synthase to $\mathrm{PGD}_{2}$, which displays pro-inflammatory and provocative actions on leukocytes and airway tissues [87]. However, $\mathrm{PGD}_{2}$ is further dehydrated to produce PGs of the $\mathrm{J}$ series, including $\Delta^{12-14}-\mathrm{PGJ}_{2}\left(\mathrm{PGJ}_{2}\right)$ and $15 \mathrm{~d}-\mathrm{PGJ} \mathrm{J}_{2}$. It has been proposed that the induction of COX-2 during resolution of inflammation is necessary for the formation of cyclopentenone PGs (cyPGs) that can transduce counter-regulatory effects via activation of peroxisome proliferator-activated receptor (PPAR)- $\gamma$ (table 2) [54, 79]. For example, the cyclopentenone $15 \mathrm{~d}_{-}-\mathrm{PG}_{2}$ inhibits the expression of vascular cell adhesion molecule (CD106) and intercellular adhesion molecule (CD54) on human umbilical vein endothelial cells [88]. The actions of $15 \mathrm{~d}-\mathrm{PGJ}_{2}$ contrast to those of LXs in that they inhibit, rather than augment, macrophage activity while having little effect on PMNs (table 1) [89]. In addition, pharmacological concentrations of $15 \mathrm{~d}-\mathrm{PGJ}_{2}$ can dampen lymphocyte proliferation and interleukin (IL)-2 production [90, 91]. These cell type-specific actions are highlighted by the evidence that $15 \mathrm{~d}-\mathrm{PGJ}_{2}$ blocks monocyte adhesion to human aortic vessels while having no effect on PMN. 15d-PGJ 2 also inhibits CC chemokine ligand (CCL)2 (monocyte chemoattractant protein-1) expression on endothelial cells, but not CCL8 (IL-8) [27].

\section{Role of cyclopentenones in lung disease}

Cyclopentenones can promote resolution of ALI. 15d-PGJ 2 protects mice from ALI by activating PPAR- $\gamma$ and the transcription factor Nrf2 (nuclear factor erythroid 2-related factor 2) that in turn transduces a number of genes to protect against oxidative damage $[92,93] .15 d_{-}-\mathrm{PGJ}_{2}$ can serve as a ligand for PPAR- $\alpha$ and PPAR- $\gamma$, and display protective actions in a murine model of allergic airway inflammation [94].

\section{Resolvins}

Resolvins (resolution phase interaction products) are omega-3 fatty acid derived anti-inflammatory lipids that were originally identified in spontaneously resolving exudates [95, 96]. Resolvins are organised into different series, depending upon the origin of the lipid. Resolvins of the D series (e.g. RvD1) are derived from docosahexaenoic acid (DHA; C22:6) and resolvins of the E series (e.g. RvE1) are derived from eicosapentaenoic acid (EPA; C20:5) [6].

Resolvins are generated in human whole blood with enzymatic conversion of DHA to 17S-hydroxy-containing D-series resolvins. Generation of these compounds is markedly increased in the presence of aspirin $[95,96]$. Endothelial cells grown under hypoxic conditions and treated with aspirin convert DHA into 17R-hydroxy-DHA by aspirin acetylated COX-2 to give rise to 
the 17R-Resolvin D series. 17R-hydroxy-DHA is also a substrate for human PMN in the formation of two sets of di- and trihydroxy products. Enzymatic oxygenation of 17R-hydroxyDHA at carbon 7 leads to aspirin-triggered RvD1 (AT-RvD1) and AT-RvD2. When 17R-hydroxy-DHA is oxygenated at carbon 4, AT-RvD3 and AT-RvD4 are generated [6]. In vitro, endothelial cells and brain-derived microglial cells treated with aspirin convert EPA to 18R-hydroxyeicosapentaenoic acid (18RHEPE) and 15R-HEPE. Both 18R- and 15R-HEPE can be rapidly converted by activated PMN to a 5(6)-epoxide-containing molecule, which is then converted to the bioactive 5,12,18Rtrihydroxyeicosapentaenoic acid (RvE1) [95].

Resolvins of both the D and E series exert potent antiinflammatory properties, such as inhibiting PMN migration and shortening the resolution phase of acute inflammation [97] (table 1). The first receptor for RvE1 was identified as ChemR23 [31]. ChemR23 is expressed on monocytes, macrophages and dendritic cells (DCs). Treatment with RvE1 inhibits inflammatory colitis, DC migration and IL-12 production, and attenuates nuclear factor- $\kappa \mathrm{B}$ activation (table 2) [30, 31]. Intriguingly, ChemR23 was originally discovered as a receptor for a chemotactic protein found in inflammatory exudates called Chemerin [98]. Recently, a second receptor for RvE1 was identified, namely the $\mathrm{LTB}_{4}$ receptor BLT1, which is expressed on PMNs, eosinophils, monocytes and T-cells [99, 100].

Of interest, mice have been developed that are transgenic for an omega-3 fatty acid desaturase thereby producing more omega-3 fatty acids from omega- 6 fatty acids [101]. These transgenic animals are protected from colitis in a model of gastrointestinal inflammation [102]. This protective effect was not secondary to a decrease in the pro-inflammatory lipids $\mathrm{PGE}_{2}$ and $\mathrm{LTB}_{4}$. Rather, levels of resolvins were significantly increased [102]. Omega-3 fatty acids are concentrated in fish oils and diets rich in omega-3 fatty acids can protect against asthma, cystic fibrosis, heart disease and cancer [103-105]. These newly identified omega- 3 resolvins provide a potential molecular rationale for these beneficial effects.

\section{Resolvins in lung disease}

Airway epithelial cells in cystic fibrosis and asthma display abnormalities in fatty acid metabolism with low levels of omega-3 fatty acids [106]. Enteric feeding of supplements enriched with omega-3 fatty acids improves clinical outcomes in ARDS, including time to liberation from mechanical ventilation and discharge from the intensive care unit [107]. Generation of resolvins has not yet been reported in ARDS or other respiratory illnesses. Little is known about the role of resolvins in lung disease, but as resolvins have been shown to exert anti-inflammatory effects in models of peritonitis and renal ischaemia-perfusion injury [29, 97], it is likely that resolvins would also be lung protective and promote the resolution of airway injury and inflammation.

\section{Neuroprotectin D1/protectin D1}

Protectin (P)D1 is 10R,17S-docosatriene that is generated from DHA in a 15-LO-catalysed reaction [108, 109]. In acute, spontaneously resolving murine peritonitis, new indices of resolution have been defined, including $\psi_{\max }$ (the maximal number of PMNs present), $t_{\max }$ (the time when $\psi_{\max }$ occurs) and $\mathrm{R}_{\mathrm{i}}$, (the resolution interval ( $t_{\max }$ to $t_{50}$ ) for PMN numbers to reach half the $\left.\psi_{\max }\right)$ [97]. Using this approach, PD1 was increased in the resolution exudates and had the most potent reduction in $\mathrm{R}_{\mathrm{i}}$ when compared with LXs, 15-epimer-LXs and E-series resolvins [97]. This docosatriene was subsequently named neuroprotectin D1/protectin D1 after identification of its generation by glial cells in the brain where DHA is abundantly found and its protection against ischaemic brain injury and Alzheimer's disease [108, 110, 111]. PD1 also modulates macrophage and structural cell responses to protect against renal and hepatic injury (table 1) [29, 112].

\section{Role in lung disease}

During asthma exacerbations, PD1 and its biosynthetic intermediate 17S-hydroxy-DHA are present in exhaled breath condensates, but are significantly reduced compared with amounts in exhaled breath condensates from healthy subjects [113]. In addition, PD1 is also present in inflamed murine lung homogenates. When exogenous PD1 is administered to allergen-sensitised mice prior to aerosol allergen challenge, PD1 significantly blocks leukocyte infiltration and airway hyperresponsiveness. When administered after allergic airway inflammation has been established, PD1 also accelerates the clearance of eosinophils. Thus, PD1 has intriguing properties that suggest exciting new therapeutic strategies for the treatment of asthma.

\section{Polyisoprenyl phosphates}

Many inflammatory diseases of the airways are associated with an abundance of PMNs, including ARDS, pneumonia and severe asthma $[3,114,115]$. Tissue-infiltrating PMNs can cause extensive damage to the surrounding tissue and perpetuate inflammation via the inadvertent release of noxious products, such as superoxide anions and proteases [4]. It is important that natural mechanisms exist to control PMN activation. PIPPs serve unique roles as "stop" signals for PMN. PIPPs are present in PMN membranes. Activation of PMNs initiates PIPP remodelling with presqualene diphosphate (PSDP) converted rapidly into its monophosphate form presqualene monophosphate (PSMP) [34]. PSDP, but not PSMP, dramatically reduces PMN release of superoxide anion generation (table 1) [10, 34].

Several regulatory sites of action have been uncovered for PIPPs. PSDP inhibits plant, microbial and mammalian phospholipase (PL)D (table 2) [34, 116]. This enzyme converts phosphatidylcholine to phosphatidic acid (PA) [117], which carries important intracellular signals in PMN that lead to a wide range of functional responses, including actin remodelling, granule release and activation of nicotinamide adenine dinucleotide phosphate-oxidase. Phosphatidylinisitol 3-kinase (PI3K) activity is important for early cell activation [118], and PSDP has recently been identified as a regulator of PI3K [57]. $\mathrm{LTB}_{4}$ stimulates a rapid decrease in PMN PSDP levels and increase in PI3K activity. PSDP interacts with p $110 \gamma$-PI3K as it deactivates, and in vitro, PSDP displays concentration-dependent inhibition of recombinant p110 $\gamma$-PI3K. PSDP structural mimetics have been prepared and can inhibit PLD, PI3K, PMN responses and lung inflammation in vivo $[57,116]$.

PSMP does not share PSDP's potent inhibitory properties. Upon PMN activation, PSDP is converted to PSMP by PA phosphatase domain containing 2 [119]. Functionally characterised as a 
phosphatase, this enzyme converts PSDP and farnesyl diphosphate to their monophosphates, and so was recently renamed polyisoprenyl diphosphate phosphatase (PDP)-1 (fig. 3). Expressed in PMNs and numerous human tissues, PDP-1 is a member of the lipid phosphatase/phosphotransferase (LPT) family [120]. There are five sub-groups of LPTs, including lipid phosphate phosphatases, sphingosine-1-phosphate (S1P) phosphatases, sphingomyelin synthases, lipid phosphatase-related proteins/plasticity-related genes and a group without any previously assigned function, which was called candidate sphingomyelin synthases type 2 (CSS2). PDP-1 is a member of the CSS2 family of LPTs [119].

In addition to PMNs, PDP-1 is also highly expressed in major immune organs (lung, spleen, thymus, liver and gut). This suggests that PDP-1 could play important roles in regulating cells not only of the myeloid lineage but also structural cells, macrophages, DCs and lymphocytes. S1P has recently been shown to play a crucial role in controlling the egress of lymphocytes from the thymus, lymph nodes and spleen [121]. S1P is metabolised by S1P phosphatases, suggesting that LPTs are likely to play many important roles in controlling immune responses.

\section{PSDP in lung disease}

During an experimental model of lung injury and inflammation from acid aspiration, a reciprocal relationship was present in vivo for lung PSDP and PI3K activity [57]. A new

a) Inflammatory stimuli
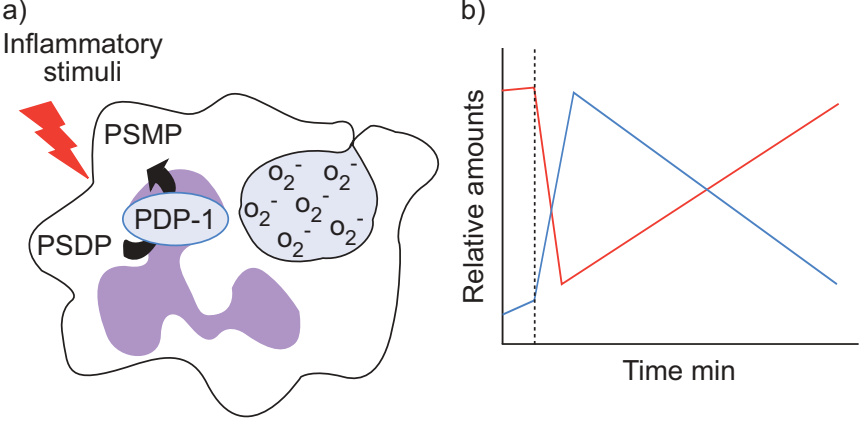

c)

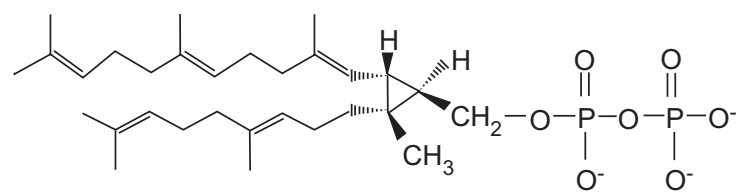

d)

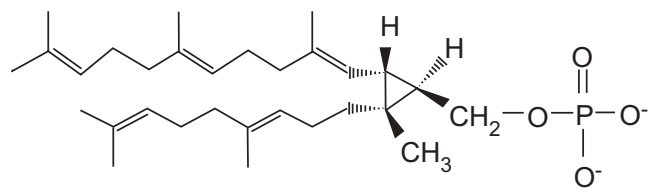

FIGURE 3. a) Illustration and b) time course of presqualene diphosphate (PSDP) remodelling in human polymorphonuclear leukocytes (PMNs). PSDP is an intracellular counter-regulatory molecule present in nanomolar quantities in freshly isolated PMNs. Activation by inflammatory stimuli (.........) results in the rapid and transient conversion of PSDP (red) to presqualene monophosphate (PSMP; blue) concurrent with functional responses, such as superoxide anion $\left(\mathrm{O}_{2}{ }^{-}\right)$generation. PSDP remodelling is mediated by polyisoprenyl diphosphate phosphatase-1 (PDP1). The pool of PSDP is restored within a few minutes as the cells deactivate. $c$ ) Chemical structure of PSDP; d) chemical structure of PSMP. diphosphonate PSDP structural mimetic was developed to resist phosphatase-based inactivation, and this PSDP analogue blocks human PMN activation by $\mathrm{LTB}_{4}$ and murine lung PI3K activity and inflammation. These findings indicate that PSDP is an endogenous PI3K inhibitor, and suggest that in inflammatory diseases characterised by excessive PMN activation, PIPPs can serve as structural templates for an anti-PMN therapeutic strategy to limit tissue injury associated with ARDS.

\section{CELLULAR EVENTS IN RESOLUTION}

\section{Apoptosis and phagocytosis}

During an inflammatory response, there is a substantial increase in the number of immune cells that accumulate in a tissue. In addition to blocking further leukocyte recruitment, leukocytes already present can either exit the inflamed tissue via draining lymphatics or undergo programmed cell death for nonphlogistic clearance by phagocytes [122]. Apoptosis and resolution of inflammation are intrinsically linked, as impairment of either apoptosis or clearance of apoptotic cells leads to chronic inflammation and auto-immunity [123]. Similarly, enhancement of apoptosis can accelerate resolution of an inflammatory response [124]. LXs promote phagocytosis of apoptotic PMNs by macrophages [18]. This process further modulates the inflammatory milieu by releasing anti-inflammatory transforming growth factor- $\beta$ that can convert naïve precursors to regulatory T-cells [125]. After ingestion of apopotic cells, macrophages also release counter-regulatory lipid mediators, including $\mathrm{PGE}_{2}, \mathrm{PGF}_{1}-\alpha$ and LXs [126, 127].

\section{Egress of leukocytes during resolution}

At the start of an inflammatory response, cells are recruited to an inflammatory focus by specific chemoattractants that orchestrate the recruitment of leukocyte subsets, beginning with PMNs, followed by eosinophils, monocytes/macrophages and lymphocytes $[128,129]$. Regulated chemokine production is essential for the normal, physiological migration of leukocytes and for the recruitment of leukocytes during an inflammatory response [130]. Altered chemokine production is often a feature of chronic inflammation, with increased leukocyte recruitment and retention within involved tissues [131]. Inflammatory microenvironments modulate egress of leukocytes by specific chemokine receptor expression, e.g. T-cells can utilise CC chemokine receptor 7 to exit via afferent lymphatics [132, 133]. Similarly, PMN can be cleared from inflamed tissue by increasing expression of the chemokine receptor CXCR4 to return to bone marrow in a stromal-derived factor-1-directed manner [134]. Pro-resolving lipid mediators are potent regulators of chemokine expression [33]. Modifications of tissue stroma with select chemokines can retain specific leukocytes and compromise resolution [135, 136].

As inflammation resolves, chemokines need to be removed from the microenvironment to halt further leukocyte recruitment. Towards this end, the "silent" chemokine receptor D6 plays an important role in scavenging inflammatory, but not constitutive chemokines [137]. D6 knockout mice fail to resolve acute inflammatory responses, suggesting that D6 has important roles in resolution [138]. Infiltrating leukocytes can also upregulate select chemokine receptors as they undergo apoptosis, in order to sequester chemokines and so prevent further leukocyte recruitment [33]. LXs are potent stimuli for 
increased clearance of apoptotic PMNs, but little is known regarding the impact of LXs or pro-resolution lipids on leukocyte egress [18].

\section{Resolution of inflammation and host defence}

Resolution of inflammation differs from immunosuppression, partly by the promotion of host defence. Of interest, LXs enhance mucosal host defence by controlling pathogeninduced inflammatory responses [20, 47] and inducing BPI expression [22]. BPI is a $55 \mathrm{kDa}$ protein released from PMN and epithelial mucosa. BPI disrupts the inner and outer lipid membranes of Gram-negative bacteria, enhances phagocytosis of bacteria and sequesters lipopolysaccharides [139]. Exposure of epithelial cells to $\mathrm{LXA}_{4}$ or ATL upregulates BPI and increases gastrointestinal epithelial killing of salmonella [22]. $\mathrm{LXA}_{4}$ and RvE1 also protect rabbits from Porphyromonas gingivalis-induced periodontal disease, demonstrating that pro-resolution molecules enhance, rather than impair, host defence in vivo [140].

\section{Therapeutic implications}

Many of the current therapeutic targets of inflammatory diseases focus on blocking the initiating or amplifying mediators of inflammation. While this strategy has been beneficial in some clinical conditions, there remain substantial unmet clinical needs for common inflammatory lung diseases, including asthma and ARDS. Rather than blocking early or select pro-inflammatory mediators, an alternative therapeutic strategy might emphasise mimetics of LXs, cyPGs, resolvins, protectins, PSDP or other natural counter-regulatory molecules that accelerate resolution of inflammation. Metabolically stable analogues of some of these compounds have been developed and display potent in vivo protective actions in several model systems [116, 141].

Of interest, anti-inflammatory therapies can impact the formation or actions of pro-resolution compounds. For example, aspirin promotes formation of 15-epimer-LXs and resolvins [17, 96]. Because of concerns for precipitating asthma, this agent is rarely used, despite its potential therapeutic benefits [142]. Glucorcorticoids are commonly used to control asthma and, in addition to increasing the ALX ligand annexin-1 (vida supra), can increase PMN expression of the ALX receptors [64]. Moreover, some anti-inflammatory experimental agents, including a 5-LOinteracting protein (FLAP) inhibitor (BayX-1005), can both decrease LT and increase LX formation in vivo [143].

\section{CONCLUSION}

The resolution of inflammation is an integral part of the physiological response to tissue injury and infection. Elucidation of resolution mechanisms has led to its recognition as a fundamental homeostatic process. In health, establishment of resolution signalling pathways is initiated early, at the very start of acute inflammatory responses. The kinetics for the formation of pro-resolving mediators is highly regulated and linked to cellular trafficking events in inflammation. Discovery of endogenous chemical agonists for resolution and their signalling pathways provides opportunities for the development of new therapeutic strategies and to gain further insights into the pathophysiology of chronic and severe inflammatory lung diseases, such as asthma and acute respiratory distress syndrome. A better understanding of the mechanisms of resolution in airway inflammation may provide new treatment options for the excess morbidity and mortality associated with these and other common respiratory conditions.

\section{ACKNOWLEDGEMENTS}

The authors would like to acknowledge C. Schneider (Brigham and Women's Hospital, Boston, MA, USA) for expert assistance in manuscript preparation.

\section{REFERENCES}

1 Vandenplas O, Toren K, Blanc PD. Health and socioeconomic impact of work-related asthma. Eur Respir J 2003; 22: 689-697.

2 Busse WW, Lemanske RF Jr. Asthma. N Engl J Med 2001; 344: 350-362.

3 Ware LB, Matthay MA. The acute respiratory distress syndrome. N Engl J Med 2000; 342: 1334-1349.

4 Nathan C. Points of control in inflammation. Nature 2002; 420: 846-852.

5 Serhan CN, Savill J. Resolution of inflammation: the beginning programs the end. Nat Immunol 2005; 6: 1191-1197.

6 Serhan CN. Resolution phases of inflammation: novel endogenous anti-inflammatory and proresolving lipid mediators and pathways. Annu Rev Immunol 2007; 25: 101-137.

7 Serhan $\mathrm{CN}$, Brain SD, Buckley CD, et al. Resolution of inflammation: state of the art, definitions and terms. FASEB J 2007; 21: 325-332.

8 Colgan SP, Serhan CN, Parkos CA, Delp-Archer C, Madara JL. Lipoxin A4 modulates transmigration of human neutrophils across intestinal epithelial monolayers. J Clin Invest 1993; 92: 75-82.

9 Serhan CN, Maddox JF, Petasis NA, et al. Design of lipoxin A4 stable analogs that block transmigration and adhesion of human neutrophils. Biochemistry 1995; 34: 14609-14615.

10 Levy BD, Fokin VV, Clark JM, Wakelam MJ, Petasis NA, Serhan CN. Polyisoprenyl phosphate (PIPP) signaling regulates phospholipase D activity: a "stop" signaling switch for aspirin-triggered lipoxin A4. FASEB J 1999; 13: 903-911.

11 Gewirtz AT, Fokin VV, Petasis NA, Serhan CN, Madara JL. LXA4, aspirin-triggered 15-epi-LXA4, and their analogs selectively downregulate PMN azurophilic degranulation. Am J Physiol 1999; 276: C988-C994.

12 Bandeira-Melo C, Bozza PT, Diaz BL, et al. Cutting edge: lipoxin (LX) $\mathrm{A}_{4}$ and aspirin-triggered 15-epi-LXA $\mathrm{L}_{4}$ block allergen-induced eosinophil trafficking. J Immunol 2000; 164: 2267-2271.

13 Soyombo O, Spur BW, Lee TH. Effects of lipoxin A4 on chemotaxis and degranulation of human eosinophils stimulated by platelet-activating factor and $N$-formyl-Lmethionyl-L-leucyl-L-phenylalanine. Allergy 1994; 49 . 230-234.

14 Ariel A, Chiang N, Arita M, Petasis NA, Serhan CN. Aspirin-triggered lipoxin A4 and B4 analogs block extracellular signal-regulated kinase-dependent TNF- $\alpha$ secretion from human T cells. J Immunol 2003; 170: 6266-6272.

15 Ramstedt U, Serhan CN, Nicolaou KC, Webber SE, Wigzell H, Samuelsson B. Lipoxin A-induced inhibition 
of human natural killer cell cytotoxicity: studies on stereospecificity of inhibition and mode of action. $J$ Immunol 1987; 138: 266-270.

16 Maddox JF, Serhan CN. Lipoxin A4 and B4 are potent stimuli for human monocyte migration and adhesion: selective inactivation by dehydrogenation and reduction. J Exp Med 1996; 183: 137-146.

17 Takano T, Fiore S, Maddox JF, Brady HR, Petasis NA, Serhan CN. Aspirin-triggered 15-epi-lipoxin A4 (LXA4) and LXA4 stable analogues are potent inhibitors of acute inflammation: evidence for anti-inflammatory receptors. $J$ Exp Med 1997; 185: 1693-1704.

18 Godson C, Mitchell S, Harvey K, Petasis NA, Hogg N, Brady HR. Cutting edge: lipoxins rapidly stimulate nonphlogistic phagocytosis of apoptotic neutrophils by monocyte-derived macrophages. J Immunol 2000; 164: 1663-1667.

19 Aliberti J, Hieny S, Reis e Sousa C, Serhan CN, Sher A. Lipoxin-mediated inhibition of IL-12 production by DCs: a mechanism for regulation of microbial immunity. Nat Immunol 2002; 3: 76-82.

20 Bafica A, Scanga CA, Serhan C, et al. Host control of Mycobacterium tuberculosis is regulated by 5-lipoxygenasedependent lipoxin production. J Clin Invest 2005; 115: 1601-1606.

21 Gewirtz AT, McCormick B, Neish AS, et al. Pathogeninduced chemokine secretion from model intestinal epithelium is inhibited by lipoxin A4 analogs. J Clin Invest 1998; 101: 1860-1869.

22 Canny G, Levy O, Furuta GT, et al. Lipid mediatorinduced expression of bactericidal/permeability-increasing protein (BPI) in human mucosal epithelia. Proc Natl Acad Sci USA 2002; 99: 3902-3907.

23 Sodin-Semrl S, Taddeo B, Tseng D, Varga J, Fiore S. Lipoxin A4 inhibits IL-1 $\beta$-induced IL-6, IL-8, and matrix metalloproteinase-3 production in human synovial fibroblasts and enhances synthesis of tissue inhibitors of metalloproteinases. J Immunol 2000; 164: 2660-2666.

24 Brezinski ME, Gimbrone MA Jr, Nicolaou KC, Serhan CN. Lipoxins stimulate prostacyclin generation by human endothelial cells. FEBS Lett 1989; 245: 167-172.

25 Papayianni A, Serhan CN, Brady HR. Lipoxin A4 and B4 inhibit leukotriene-stimulated interactions of human neutrophils and endothelial cells. J Immunol 1996; 156: 2264-2272.

26 Bonnans C, Fukunaga K, Levy MA, Levy BD. Lipoxin $\mathrm{A}_{4}$ regulates bronchial epithelial cell responses to acid injury. Am J Pathol 2006; 168: 1064-1072.

27 Panzer U, Schneider A, Guan Y, et al. Effects of different PPAR $\gamma$-agonists on MCP-1 expression and monocyte recruitment in experimental glomerulonephritis. Kidney Int 2002; 62: 455-464.

28 Chatterjee BE, Yona S, Rosignoli G, et al. Annexin 1deficient neutrophils exhibit enhanced transmigration in vivo and increased responsiveness in vitro. J Leukoc Biol 2005; 78: 639-646.

29 Duffield JS, Hong S, Vaidya VS, et al. Resolvin D series and protectin D1 mitigate acute kidney injury. J Immunol 2006; 177: 5902-5911.

30 Arita M, Yoshida M, Hong S, et al. Resolvin E1, an endogenous lipid mediator derived from omega-3 eicosapentaenoic acid, protects against 2,4,6-trinitrobenzene sulfonic acid-induced colitis. Proc Natl Acad Sci USA 2005; 102: 7671-7676.

31 Arita M, Bianchini F, Aliberti J, et al. Stereochemical assignment, antiinflammatory properties, and receptor for the omega-3 lipid mediator resolvin E1. J Exp Med 2005; 201: 713-722.

32 Hasturk H, Kantarci A, Ohira T, et al. RvE1 protects from local inflammation and osteoclast-mediated bone destruction in periodontitis. FASEB J 2006; 20: 401-403.

33 Ariel A, Fredman G, Sun YP, et al. Apoptotic neutrophils and $\mathrm{T}$ cells sequester chemokines during immune response resolution through modulation of CCR5 expression. Nat Immunol 2006; 7: 1209-1216.

34 Levy BD, Petasis NA, Serhan CN. Polyisoprenyl phosphates in intracellular signalling. Nature 1997; 389: 985-990.

35 Serhan CN, Hamberg M, Samuelsson B. Lipoxins: novel series of biologically active compounds formed from arachidonic acid in human leukocytes. Proc Natl Acad Sci USA 1984; 81: 5335-5339.

36 Serhan CN, Hamberg M, Samuelsson B. Trihydroxytetraenes: a novel series of compounds formed from arachidonic acid in human leukocytes. Biochem Biophys Res Commun 1984; 118: 943-949.

37 Levy BD, De Sanctis GT, Devchand PR, et al. Multipronged inhibition of airway hyper-responsiveness and inflammation by lipoxin $\mathrm{A}_{4}$. Nat Med 2002; 8: 1018-1023.

38 Fiore S, Serhan CN. Formation of lipoxins and leukotrienes during receptor-mediated interactions of human platelets and recombinant human granulocyte/macrophage colony-stimulating factor-primed neutrophils. J Exp Med 1990; 172: 1451-1457.

39 Serhan CN, Sheppard KA. Lipoxin formation during human neutrophil-platelet interactions. Evidence for the transformation of leukotriene A4 by platelet 12-lipoxygenase in vitro. J Clin Invest 1990; 85: 772-780.

40 Levy BD, Romano M, Chapman HA, Reilly JJ, Drazen J, Serhan CN. Human alveolar macrophages have 15lipoxygenase and generate 15(S)-hydroxy-5,8,11-cis-13trans-eicosatetraenoic acid and lipoxins. J Clin Invest 1993; 92: 1572-1579.

41 Vane JR. Inhibition of prostaglandin synthesis as a mechanism of action for aspirin-like drugs. Nat New Biol 1971; 231: 232-235.

42 Claria J, Serhan CN. Aspirin triggers previously undescribed bioactive eicosanoids by human endothelial cellleukocyte interactions. Proc Natl Acad Sci USA 1995; 92: 9475-9479.

43 Paul-Clark MJ, Van Cao T, Moradi-Bidhendi N, Cooper D, Gilroy DW. 15-epi-lipoxin A4-mediated induction of nitric oxide explains how aspirin inhibits acute inflammation. J Exp Med 2004; 200: 69-78.

44 Claria J, Lee MH, Serhan CN. Aspirin-triggered lipoxins (15-epi-LX) are generated by the human lung adenocarcinoma cell line (A549)-neutrophil interactions and are potent inhibitors of cell proliferation. Mol Med 1996; 2: 583-596.

45 Chiang N, Takano T, Clish CB, Petasis NA, Tai HH, Serhan CN. Aspirin-triggered 15-epi-lipoxin A4 (ATL) generation by human leukocytes and murine peritonitis 
exudates: development of a specific 15-epi-LXA4 ELISA. J Pharmacol Exp Ther 1998; 287: 779-790.

46 Serhan CN, Fiore S, Brezinski DA, Lynch S. Lipoxin A4 metabolism by differentiated HL-60 cells and human monocytes: conversion to novel 15-oxo and dihydro products. Biochemistry 1993; 32: 6313-6319.

47 Machado FS, Johndrow JE, Esper L, et al. Anti-inflammatory actions of lipoxin A4 and aspirin-triggered lipoxin are SOCS-2 dependent. Nat Med 2006; 12: 330-334.

48 Chiang N, Fierro IM, Gronert K, Serhan CN. Activation of lipoxin $\mathrm{A}_{4}$ receptors by aspirin-triggered lipoxins and select peptides evokes ligand-specific responses in inflammation. J Exp Med 2000; 191: 1197-1208.

49 Gronert K, Gewirtz A, Madara JL, Serhan CN. Identification of a human enterocyte lipoxin A4 receptor that is regulated by interleukin (IL)-13 and interferon $\gamma$ and inhibits tumor necrosis factor $\alpha$-induced IL- 8 release. J Exp Med 1998; 187: 1285-1294.

50 Simchowitz L, Fiore S, Serhan CN. Carrier-mediated transport of lipoxin A4 in human neutrophils. Am J Physiol 1994; 267: C1525-C1534.

51 Ohira T, Bannenberg G, Arita M, et al. A stable aspirintriggered lipoxin A4 analog blocks phosphorylation of leukocyte-specific protein 1 in human neutrophils. J Immunol 2004; 173: 2091-2098.

52 Reville K, Crean JK, Vivers S, Dransfield I, Godson C. Lipoxin A4 redistributes myosin IIA and Cdc42 in macrophages: implications for phagocytosis of apoptotic leukocytes. J Immunol 2006; 176: 1878-1888.

53 Planagumà A, Titos E, López-Parra M, et al. Aspirin (ASA) regulates 5-lipoxygenase activity and peroxisome proliferator-activated receptor $\alpha$-mediated CINC-1 release in rat liver cells: novel actions of lipoxin A4 (LXA4) and ASA-triggered 15-epi-LXA4. FASEB J 2002; 16: 1937-1939.

54 Ricote M, Li AC, Willson TM, Kelly CJ, Glass CK. The peroxisome proliferator-activated receptor- $\gamma$ is a negative regulator of macrophage activation. Nature 1998; 391: 79-82.

55 Perez-Sala D, Cernuda-Morollon E, Canada FJ. Molecular basis for the direct inhibition of AP-1 DNA binding by 15-deoxy- $\Delta$ 12,14-prostaglandin J2. J Biol Chem 2003; 278: 51251-51260.

56 Levy BD, Serhan CN. Polyisoprenyl phosphates: natural antiinflammatory lipid signals. Cell Mol Life Sci 2002; 59: 729-741.

57 Bonnans C, Fukunaga K, Keledjian R, Petasis NA, Levy BD. Regulation of phosphatidylinositol 3-kinase by polyisoprenyl phosphates in neutrophil-mediated tissue injury. J Exp Med 2006; 203: 857-863.

58 Guyre PM, Girard MT, Morganelli PM, Manganiello PD. Glucocorticoid effects on the production and actions of immune cytokines. J Steroid Biochem 1988; 30: 89-93.

59 Pype JL, Dupont LJ, Menten P, et al. Expression of monocyte chemotactic protein (MCP)-1, MCP-2, and MCP-3 by human airway smooth-muscle cells. Modulation by corticosteroids and T-helper 2 cytokines. Am J Respir Cell Mol Biol 1999; 21: 528-536.

60 Cronstein BN, Kimmel SC, Levin RI, Martiniuk F, Weissmann G. A mechanism for the antiinflammatory effects of corticosteroids: the glucocorticoid receptor regulates leukocyte adhesion to endothelial cells and expression of endothelial-leukocyte adhesion molecule 1 and intercellular adhesion molecule 1. Proc Natl Acad Sci USA 1992; 89: 9991-9995.

61 Caulfield J, Fernandez M, Snetkov V, Lee T, Hawrylowicz C. CXCR4 expression on monocytes is up-regulated by dexamethasone and is modulated by autologous CD3+ T cells. Immunology 2002; 105: 155-162.

62 Curnow SJ, Wloka K, Faint JM, et al. Topical glucocorticoid therapy directly induces up-regulation of functional CXCR4 on primed T lymphocytes in the aqueous humor of patients with uveitis. J Immunol 2004; 172: 7154-7161.

63 Evans RM. The steroid and thyroid hormone receptor superfamily. Science 1988; 240: 889-895.

64 Hashimoto A, Murakami Y, Kitasato H, Hayashi I, Endo H. Glucocorticoids co-interact with lipoxin $\mathrm{A}_{4}$ via lipoxin $\mathrm{A}_{4}$ receptor (ALX) up-regulation. Biomed Pharmacother 2007; 61: 209.

65 Perretti M, Chiang N, La M, et al. Endogenous lipid- and peptide-derived anti-inflammatory pathways generated with glucocorticoid and aspirin treatment activate the lipoxin A4 receptor. Nat Med 2002; 8: 1296-1302.

66 Francis JW, Balazovich KJ, Smolen JE, Margolis DI, Boxer LA. Human neutrophil annexin I promotes granule aggregation and modulates $\mathrm{Ca}^{2+}$-dependent membrane fusion. J Clin Invest 1992; 90: 537-544.

67 Perretti M, Christian H, Wheller SK, et al. Annexin I is stored within gelatinase granules of human neutrophil and mobilized on the cell surface upon adhesion but not phagocytosis. Cell Biol Int 2000; 24: 163-174.

68 Lim LH, Solito E, Russo-Marie F, Flower RJ, Perretti M. Promoting detachment of neutrophils adherent to murine postcapillary venules to control inflammation: effect of lipocortin 1. Proc Natl Acad Sci USA 1998; 95: 1453514539.

69 Perretti M, Ahluwalia A, Harris JG, Harris HJ, Wheller SK, Flower RJ. Acute inflammatory response in the mouse: exacerbation by immunoneutralization of lipocortin 1. Br J Pharmacol 1996; 117: 1145-1154.

70 Gavins FN, Yona S, Kamal AM, Flower RJ, Perretti M. Leukocyte antiadhesive actions of annexin 1: ALXR- and FPR-related anti-inflammatory mechanisms. Blood 2003; 101: 4140-4147.

71 Lee $\mathrm{TH}$, Crea AE, Gant V, et al. Identification of lipoxin A4 and its relationship to the sulfidopeptide leukotrienes C4, D4, and E4 in the bronchoalveolar lavage fluids obtained from patients with selected pulmonary diseases. Am Rev Respir Dis 1990; 141: 1453-1458.

72 Sanak M, Levy BD, Clish CB, et al. Aspirin-tolerant asthmatics generate more lipoxins than aspirin-intolerant asthmatics. Eur Respir J 2000; 16: 44-49.

73 Vachier I, Bonnans C, Chavis C, et al. Severe asthma is associated with a loss of LX4, an endogenous antiinflammatory compound. J Allergy Clin Immunol 2005; 115: 55-60.

74 Levy BD, Bonnans C, Silverman ES, Palmer LJ, Marigowda G, Israel E. Diminished lipoxin biosynthesis in severe asthma. Am J Respir Crit Care Med 2005; 172: 824-830.

75 Karp CL, Flick LM, Park KW, et al. Defective lipoxinmediated anti-inflammatory activity in the cystic fibrosis airway. Nat Immunol 2004; 5: 388-392. 
76 Starosta V, Ratjen F, Rietschel E, Paul K, Griese M. Antiinflammatory cytokines in cystic fibrosis lung disease. Eur Respir J 2006; 28: 581-587.

77 Fukunaga K, Kohli P, Bonnans C, Fredenburgh LE, Levy BD. Cyclooxygenase 2 plays a pivotal role in the resolution of acute lung injury. J Immunol 2005; 174: 50335039 .

78 Funk CD. Prostaglandins and leukotrienes: advances in eicosanoid biology. Science 2001; 294: 1871-1875.

79 Gilroy DW, Colville-Nash PR, Willis D, Chivers J, PaulClark MJ, Willoughby DA. Inducible cyclooxygenase may have anti-inflammatory properties. Nat Med 1999; 5: 698-701.

80 Bandeira-Melo C, Serra MF, Diaz BL, et al. Cyclooxygenase-2-derived prostaglandin E2 and lipoxin A4 accelerate resolution of allergic edema in Angiostrongylus costaricensis-infected rats: relationship with concurrent eosinophilia. J Immunol 2000; 164: 1029-1036.

81 Levy BD, Clish CB, Schmidt B, Gronert K, Serhan CN. Lipid mediator class switching during acute inflammation: signals in resolution. Nat Immunol 2001; 2: 612-619.

82 Samuelsson B, Dahlen SE, Lindgren JA, Rouzer CA, Serhan CN. Leukotrienes and lipoxins: structures, biosynthesis, and biological effects. Science 1987; 237: 11711176.

83 Peters-Golden M, Canetti C, Mancuso P, Coffey MJ. Leukotrienes: underappreciated mediators of innate immune responses. J Immunol 2005; 174: 589-594.

84 Gosselin J, Borgeat P, Flamand L. Leukotriene B4 protects latently infected mice against murine cytomegalovirus reactivation following allogeneic transplantation. J Immunol 2005; 174: 1587-1593.

85 Schultz MJ, Wijnholds J, Peppelenbosch MP, et al. Mice lacking the multidrug resistance protein 1 are resistant to Streptococcus pneumoniae-induced pneumonia. I Immunol 2001; 166: 4059-4064.

86 Benjamim CF, Canetti C, Cunha FQ, Kunkel SL, Peters-Golden M. Opposing and hierarchical roles of leukotrienes in local innate immune versus vascular responses in a model of sepsis. J Immunol 2005; 174: 1616-1620.

87 Fujitani Y, Kanaoka Y, Aritake K, Uodome N, OkazakiHatake K, Urade Y. Pronounced eosinophilic lung inflammation and Th2 cytokine release in human lipocalin-type prostaglandin D synthase transgenic mice. J Immunol 2002; 168: 443-449.

88 Zernecke A, Erl W, Fraemohs L, Lietz M, Weber C. Suppression of endothelial adhesion molecule up-regulation with cyclopentenone prostaglandins is dissociated from IкB- $\alpha$ kinase inhibition and cell death induction. FASEB J 2003; 17: 1099-1101.

89 Gilroy DW, Lawrence T, Perretti M, Rossi AG. Inflammatory resolution: new opportunities for drug discovery. Nat Rev Drug Discov 2004; 3: 401-416.

90 Trivedi SG, Newson J, Rajakariar R, et al. Essential role for hematopoietic prostaglandin D2 synthase in the control of delayed type hypersensitivity. Proc Natl Acad Sci USA 2006; 103: 5179-5184.

91 Kobayashi Y, Ueki S, Mahemuti G, et al. Physiological levels of 15-deoxy- $\Delta 12,14$-prostaglandin J2 prime eotaxin-induced chemotaxis on human eosinophils through peroxisome proliferator-activated receptor- $\gamma$ ligation. J Immunol 2005; 175: 5744-5750.

92 Genovese T, Cuzzocrea S, Di Paola R, et al. Effect of rosiglitazone and 15-deoxy- $\Delta^{12,14}$-prostaglandin $\mathrm{J} 2$ on bleomycin-induced lung injury. Eur Respir J 2005; 25: 225-234.

93 Mochizuki M, Ishii $Y$, Itoh $K$, et al. Role of 15-deoxy $\Delta^{12,14}$ prostaglandin $\mathrm{J} 2$ and Nrf2 pathways in protection against acute lung injury. Am J Respir Crit Care Med 2005; 171: 1260-1266.

94 Woerly G, Honda K, Loyens M, et al. Peroxisome proliferator-activated receptors $\alpha$ and $\gamma$ down-regulate allergic inflammation and eosinophil activation. J Exp Med 2003; 198: 411-421.

95 Serhan CN, Clish CB, Brannon J, Colgan SP, Chiang N, Gronert K. Novel functional sets of lipid-derived mediators with antiinflammatory actions generated from omega-3 fatty acids via cyclooxygenase 2-nonsteroidal antiinflammatory drugs and transcellular processing. $J$ Exp Med 2000; 192: 1197-1204.

96 Serhan CN, Hong S, Gronert K, et al. Resolvins: a family of bioactive products of omega-3 fatty acid transformation circuits initiated by aspirin treatment that counter proinflammation signals. J Exp Med 2002; 196: 1025-1037.

97 Bannenberg GL, Chiang N, Ariel A, et al. Molecular circuits of resolution: formation and actions of resolvins and protectins. J Immunol 2005; 174: 4345-4355.

98 Wittamer V, Franssen JD, Vulcano M, et al. Specific recruitment of antigen-presenting cells by chemerin, a novel processed ligand from human inflammatory fluids. J Exp Med 2003; 198: 977-985.

99 Arita M, Ohira T, Sun YP, Elangovan S, Chiang N, Serhan CN. Resolvin E1 selectively interacts with leukotriene B4 receptor BLT1 and ChemR23 to regulate inflammation. J Immunol 2007; 178: 3912-3917.

100 Yokomizo T, Izumi T, Chang K, Takuwa Y, Shimizu T. A G-protein-coupled receptor for leukotriene B4 that mediates chemotaxis. Nature 1997; 387: 620-624.

101 Kang JX, Wang J, Wu L, Kang ZB. Transgenic mice: fat-1 mice convert n-6 to $n-3$ fatty acids. Nature 2004; 427: 504.

102 Hudert CA, Weylandt KH, Lu Y, et al. Transgenic mice rich in endogenous omega-3 fatty acids are protected from colitis. Proc Natl Acad Sci USA 2006; 103: 11276-11281.

103 Camuesco D, Comalada M, Concha A, et al. Intestinal anti-inflammatory activity of combined quercitrin and dietary olive oil supplemented with fish oil, rich in EPA and DHA (n-3) polyunsaturated fatty acids, in rats with DSS-induced colitis. Clin Nutr 2006; 25: 466-476.

104 Marchioli R, Barzi F, Bomba E, et al. Early protection against sudden death by $n-3$ polyunsaturated fatty acids after myocardial infarction: time-course analysis of the results of the Gruppo Italiano per lo Studio della Sopravvivenza nell'Infarto Miocardico (GISSI)Prevenzione. Circulation 2002; 105: 1897-1903.

105 Mickleborough TD, Lindley MR, Ionescu AA, Fly AD. Protective effect of fish oil supplementation on exerciseinduced bronchoconstriction in asthma. Chest 2006; 129: 39-49.

106 Freedman SD, Blanco PG, Zaman MM, et al. Association of cystic fibrosis with abnormalities in fatty acid metabolism. N Engl J Med 2004; 350: 560-569. 
107 Gadek JE, DeMichele SJ, Karlstad MD, et al. Effect of enteral feeding with eicosapentaenoic acid, $\gamma$-linolenic acid, and antioxidants in patients with acute respiratory distress syndrome. Enteral Nutrition in ARDS Study Group. Crit Care Med 1999; 27: 1409-1420.

108 Hong S, Gronert K, Devchand PR, Moussignac RL, Serhan CN. Novel docosatrienes and 17S-resolvins generated from docosahexaenoic acid in murine brain, human blood, and glial cells. Autacoids in anti-inflammation.:: J Biol Chem 2003; 278: 14677-14687.

109 Serhan CN, Gotlinger K, Hong S, et al. Anti-inflammatory actions of neuroprotectin D1/protectin D1 and its natural stereoisomers: assignments of dihydroxy-containing docosatrienes. J Immunol 2006; 176: 1848-1859.

110 Marcheselli VL, Hong S, Lukiw WJ, et al. Novel docosanoids inhibit brain ischemia-reperfusion-mediated leukocyte infiltration and pro-inflammatory gene expression. J Biol Chem 2003; 278: 43807-43817.

111 Lukiw WJ, Cui JG, Marcheselli VL, et al. A role for docosahexaenoic acid-derived neuroprotectin D1 in neural cell survival and Alzheimer disease. J Clin Invest 2005; 115: 2774-2783.

112 Gonzalez-Periz A, Planaguma A, Gronert K, et al. Docosahexaenoic acid (DHA) blunts liver injury by conversion to protective lipid mediators: protectin D1 and 17S-hydroxy-DHA. FASEB J 2006; 20: 2537-2539.

113 Levy BD, Kohli P, Gotlinger K, et al. Protectin D1 is generated in asthma and dampens airway inflammation and hyperresponsiveness. J Immunol 2007; 178: 496-502.

114 Haslett C. Granulocyte apoptosis and its role in the resolution and control of lung inflammation. Am J Respir Crit Care Med 1999; 160: S5-S11.

115 Jatakanon A, Uasuf C, Maziak W, Lim S, Chung KF, Barnes PJ. Neutrophilic inflammation in severe persistent asthma. Am J Respir Crit Care Med 1999; 160: 1532-1539.

116 Levy BD, Hickey L, Morris AJ, et al. Novel polyisoprenyl phosphates block phospholipase D and human neutrophil activation in vitro and murine peritoneal inflammation in vivo. Br J Pharmacol 2005; 146: 344-351.

117 Jenkins GM, Frohman MA. Phospholipase D: a lipid centric review. Cell Mol Life Sci 2005; 62: 2305-2316.

118 Stephens L, Smrcka A, Cooke FT, Jackson TR, Sternweis PC, Hawkins PT. A novel phosphoinositide 3 kinase activity in myeloid-derived cells is activated by $\mathrm{G}$ protein $\beta \gamma$ subunits. Cell 1994; 77: 83-93.

119 Fukunaga K, Arita M, Takahashi M, Morris AJ, Pfeffer M, Levy BD. Identification and functional characterization of a presqualene diphosphate phosphatase. J Biol Chem 2006; 281: 9490-9497.

120 Sigal YJ, McDermott MI, Morris AJ. Integral membrane lipid phosphatases/phosphotransferases: common structure and diverse functions. Biochem J 2005; 387: 281-293.

121 Matloubian M, Lo CG, Cinamon G, et al. Lymphocyte egress from thymus and peripheral lymphoid organs is dependent on S1P receptor 1. Nature 2004; 427: 355-360.

122 Raff M. Cell suicide for beginners. Nature 1998; 396: 119-122.

123 Botto M, Dell'Agnola C, Bygrave AE, et al. Homozygous C1q deficiency causes glomerulonephritis associated with multiple apoptotic bodies. Nat Genet 1998; 19: 56-59.

124 Rossi AG, Sawatzky DA, Walker A, et al. Cyclindependent kinase inhibitors enhance the resolution of inflammation by promoting inflammatory cell apoptosis. Nat Med 2006; 12: 1056-1064.

125 Chen W, Jin W, Hardegen $N$, et al. Conversion of peripheral CD4+CD25- naive $\mathrm{T}$ cells to $\mathrm{CD} 4+\mathrm{CD} 25+$ regulatory $\mathrm{T}$ cells by TGF- $\beta$ induction of transcription factor Foxp3. J Exp Med 2003; 198: 1875-1886.

126 Fadok VA, Bratton DL, Konowal A, Freed PW, Westcott JY, Henson PM. Macrophages that have ingested apoptotic cells in vitro inhibit proinflammatory cytokine production through autocrine/paracrine mechanisms involving TGF- $\beta$, PGE2, and PAF. J Clin Invest 1998; 101: 890-898.

127 Freire-de-Lima CG, Xiao YQ, Gardai SJ, Bratton DL, Schiemann WP, Henson PM. Apoptotic cells, through transforming growth factor- $\beta$, coordinately induce antiinflammatory and suppress pro-inflammatory eicosanoid and NO synthesis in murine macrophages. J Biol Chem 2006; 281: 38376-38384.

128 Hurst SM, Wilkinson TS, McLoughlin RM, et al. IL-6 and its soluble receptor orchestrate a temporal switch in the pattern of leukocyte recruitment seen during acute inflammation. Immunity 2001; 14: 705-714.

129 Willoughby DA, Moore AR, Colville-Nash PR, Gilroy D. Resolution of inflammation. Int J Immunopharmacol 2000; 22: 1131-1135.

130 Campbell DJ, Kim CH, Butcher EC. Chemokines in the systemic organization of immunity. Immunol Rev 2003; 195: 58-71.

131 Lukacs NW. Role of chemokines in the pathogenesis of asthma. Nat Rev Immunol 2001; 1: 108-116.

132 Bromley SK, Thomas SY, Luster AD. Chemokine receptor CCR7 guides T cell exit from peripheral tissues and entry into afferent lymphatics. Nat Immunol 2005; 6: 895-901.

133 Debes GF, Arnold CN, Young AJ, et al. Chemokine receptor CCR7 required for $\mathrm{T}$ lymphocyte exit from peripheral tissues. Nat Immunol 2005; 6: 889-894.

134 Martin C, Burdon PC, Bridger G, Gutierrez-Ramos JC, Williams TJ, Rankin SM. Chemokines acting via CXCR2 and CXCR4 control the release of neutrophils from the bone marrow and their return following senescence. Immunity 2003; 19: 583-593.

135 Buckley CD, Pilling D, Lord JM, Akbar AN, Scheel-Toellner D, Salmon M. Fibroblasts regulate the switch from acute resolving to chronic persistent inflammation. Trends Immunol 2001; 22: 199-204.

136 Burman A, Haworth O, Hardie DL, et al. A chemokinedependent stromal induction mechanism for aberrant lymphocyte accumulation and compromised lymphatic return in rheumatoid arthritis. J Immunol 2005; 174: 16931700 .

137 Fra AM, Locati M, Otero $K$, et al. Cutting edge: scavenging of inflammatory $\mathrm{CC}$ chemokines by the promiscuous putatively silent chemokine receptor D6. $J$ Immunol 2003; 170: 2279-2282.

138 Jamieson T, Cook DN, Nibbs RJ, et al. The chemokine receptor D6 limits the inflammatory response in vivo. Nat Immunol 2005; 6: 403-411.

139 Levy O. Antimicrobial proteins and peptides of blood: templates for novel antimicrobial agents. Blood 2000; 96: 2664-2672. 
140 Serhan CN, Jain A, Marleau S, et al. Reduced inflammation and tissue damage in transgenic rabbits overexpressing 15-lipoxygenase and endogenous anti-inflammatory lipid mediators. J Immunol 2003; 171: 6856-6865.

141 Petasis NA, Akritopoulou-Zanze I, Fokin VV, et al. Design, synthesis and bioactions of novel stable mimetics of lipoxins and aspirin-triggered lipoxins. Prostaglandins Leukot Essent Fatty Acids 2005; 73: 301-321.
142 Barr RG, Kurth T, Stampfer MJ, Buring JE, Hennekens CH, Gaziano JM. Aspirin and decreased adult-onset asthma: randomized comparisons from the physicians' health study. Am J Respir Crit Care Med 2007; 175: 120-125.

143 Titos E, Claria J, Planaguma A, et al. Inhibition of 5lipoxygenase-activating protein abrogates experimental liver injury: role of Kupffer cells. J Leukoc Biol 2005; 78: 871-878. 